\title{
Heat resistance of wild Lactococcus lactis strains under a thermal gradient of cooked cheese, in milk and in mini-cheeses
}

\author{
Sophie JEANSON ${ }^{\mathrm{a}, \mathrm{b} *}$, Françoise BERTHIER ${ }^{\mathrm{a}}$, Rémy GRAPPIN ${ }^{\mathrm{a} \dagger}$, \\ Eric BEUVIER ${ }^{\mathrm{a}}$ \\ a Technologie et Analyses Laitières, INRA, BP 89, 39801 Poligny Cedex, France \\ b ITFF, l'Institut Technique Français des Fromages, zone centre, 39801 Poligny Cedex, France
}

Received 9 December 2002 - Accepted 25 March 2003

Published online 17 July 2003

\begin{abstract}
The purpose of this study was to show the advantages and limits of cultures in milk in order to predict lactococcal growth in the manufacture of cooked cheeses. Eighteen lactococci isolated from raw milk and natural starters were genetically identified as strains of Lactococcus lactis ssp. lactis or cremoris. They were characterized in pure and cocktail cultures by their growth and their acidifying and proteolytic activities, either in milk culture at $30^{\circ} \mathrm{C}$ and under a thermal gradient, or in cooked mini-cheeses. A wide diversity was found not only between pure strains, but also within a same strain cocktail depending on the conditions used. Growth in mini-cheese could not be exactly reproduced in milk culture, even when conditions were as close as possible to cheese manufacture (the same starters, milk and thermal gradient). However, milk cultures were extremely helpful in comparing the heat resistance of pure strains. Selection of mesophilic starters to be used for milk maturation during cooked cheese manufacture must consider the diversity of heat resistance among strains. This diversity may be useful in understanding the role of lactococci in the final quality of cooked cheeses.
\end{abstract}

\section{Lactococci / heat resistance / milk maturation / strain selection / cooked cheese}

Résumé - Résistance au chauffage de lactocoques sauvages pendant le gradient thermique d'une technologie à pâte pressée cuite - Comportements dans le lait et dans les mini-fromages. Ce travail a pour objectif de montrer les avantages et les limites des tests en culture lait pour prédire le comportement des lactocoques dans les fromages à pâte pressée cuite (PPC). Dix-huit lactocoques isolés de lait crus et de levains naturels ont été typés génétiquement comme des souches différentes de Lactococcus lactis ssp. lactis ou cremoris. Ils ont été caractérisés, en culture pure et en association de souches, par leur croissance et leurs activités acidifiantes et protéolytiques, soit en culture lait à $30^{\circ} \mathrm{C}$ et lors d'un gradient thermique type PPC, soit en mini-fromages de type PPC. Une grande diversité a été mise en évidence entre souches, mais aussi pour une même association de souches selon les conditions utilisées. Le comportement en mini-fromage n'a pu être reproduit exactement en culture sur lait, même dans des conditions mimant au plus près celles prévalant dans les fromages (mêmes levains, lait et gradient thermique). Cependant les cultures lait ont été

\footnotetext{
* Corresponding author: jeanson@poligny.inra.fr

$\dagger$ deceased
} 
extrêmement utiles pour comparer la résistance au chauffage des souches pures de lactocoques. La sélection des levains mésophiles servant à la maturation du lait dans la fabrication de fromages PPC doit tenir compte de leur diversité de résistance au chauffage appliqué lors des fabrications.

Lactocoque / résistance au chauffage / maturation du lait / sélection de souche / fromage à pâte pressée cuite

\section{INTRODUCTION}

Comté cheese is a French cooked cheese made from raw cows' milk. Cooked cheeses "are characterized by high "cook" temperatures $\left(50-55^{\circ} \mathrm{C}\right)$ " according to Michel and Martley [33]. The first step of manufacture is a milk maturation at a temperature of about $30^{\circ} \mathrm{C}$, with or without added mesophilic starters. Milk maturation is also commonly used in the manufacture of other cheese varieties. Lactococcus lactis sp. are extensively used in cheese manufacture [18]. They are present in the mesophilic starters added to milk for milk maturation. Manufacturers have observed, empirically, that mesophilic starters play a role in the final sensory quality of Comté cheese, but this role has never been investigated. No surveys, with the exception of Chamba [9], deal with the role of mesophilic starters in any of the cooked cheese varieties. Due to their mesophilic character and to the temperature used in the manufacture of these cheese varieties, lactococci should normally not reach a high level and should be destroyed early when the curd is cooked at a temperature above $50{ }^{\circ} \mathrm{C}$. Their role(s) should be different from those described in non-cooked cheeses where they grow to a high level during cheesemaking (about $10^{9} \mathrm{cfu} \cdot \mathrm{mg}^{-1}$ ). Their role has been widely investigated in some of these latter cheeses, such as Cheddar or Saint-Paulin [6, 28], in which lactococcal starters are identified as acidifying and flavor agents.

Wild lactococcal strains have been isolated from raw milk products, such as Camembert - a non-cooked cheese - or Pecorino Sardo - a semi-cooked cheese $[13,29,42]$ - but never from cooked cheeses, although some of them were manufactured with raw milk. There is a need to select strains for new mesophilic cheese starters. Selection tests have to be adapted to each type of cheese manufacture [11] in order to remain as close as possible to the manufacturing conditions. In 1969, Pearce [36] recommended a selection of mesophilic starters for Cheddar cheese manufacture with a simulation of the Cheddar cheese thermal gradient over the $5 \mathrm{~h}$ incubation period. In 1981, Heap and Lawrence [21] modified Pearce's test by adding rennet to the milk test cultures to improve correlation with cheese-making conditions. Wild lactococci were selected on their ability to acidify under a soft cheese thermal gradient [8], as were thermophilic streptococci and lactobacilli under thermal gradients of Grana [20, 34] and Emmental cheeses [10]. These latter studies showed important differences in the ability to acidify under a particular thermal gradient at both species and strain levels, proving that thermal gradients were pertinent for selecting starters. In all these studies, no interactions between strains were tested. These tests were always performed with one strain even though different strains of the same and different species are commonly associated in mesophilic and thermophilic starters. The results obtained in milk were never validated in cheese.

As far as we know, only Chamba [9] has rapidly described the growth kinetics of lactococci in milk under a thermal gradient used for a cooked cheese manufacture, Emmental cheese. However, no cocktail of lactococcal strains were tested and no technological characteristics were studied. Nevertheless, this may be an important point in understanding their role in the quality of 
such cheeses and in selecting them for cheese starters adapted to these specific cheese manufacturing conditions.

The present study explored the diversity of the genetic and technological characteristics of 18 wild lactococcal isolates. Three technological characteristics were tested: acidifying and proteolysis activities, and growth kinetics either at the optimal growth temperature of lactococci or under the specific thermal gradient used for Comté cheese manufacture. These characteristics were evaluated in milk, firstly with each lactococcal strain, then with two different cocktails of three lactococcal strains, and finally, one of the lactococcal cocktails was associated with the two other starter species, Streptococcus thermophilus and Lactobacillus helveticus. The two cocktails of lactococcal strains were also used as starters in three Comté-type minicheeses, manufactured from raw, microfiltered and reconstituted milk, in order to evaluate the ability of the milk tests to predict growth kinetics in cheese.

\section{MATERIALS AND METHODS}

\subsection{Bacterial strains}

\subsubsection{Pure strains of lactococci}

Eighteen isolates were phenotypically identified as Lactococcus lactis subsp. lactis in our laboratory [12]. Fourteen of them were isolated from raw cows' milk destined for different dairies (isolates numbered with discontinuity from 2001 to 2016 and 2249 to 2253) and the last four were obtained from drainage whey collected in the same dairy at the end of Comté cheese manufacture and incubated at $25{ }^{\circ} \mathrm{C}$ (isolates numbered with discontinuity from 2055 to 2063). Two of them, isolates 2013 and 2063, were Lactococcus lactis subsp. lactis biovar diacetylactis strains.

Four strains from the CNRZ collection of the Unité de Recherches Laitières et de Génétique Appliquée (INRA, Jouy-en-
Josas, France) were included in the present work: two strains of Lc. lactis subsp. lactis, CNRZ 1076 Prt+ and its variant CNRZ 1075 Prt- [23], the type strain for Lc. lactis subsp. lactis, CNRZ $142^{\mathrm{T}}$, and a strain with a lactis phenotype and a cremoris genotype, CNRZ 269 [39].

\subsubsection{Lactococcal strain cocktails}

Two cocktails were composed, each containing three of the wild lactococcal strains described above. Cocktail No. 1 contained strains 2001, 2006 and 2063 and cocktail No. 2 contained strains 2001, 2004 and 2056.

\subsubsection{Thermophilic strain cocktails}

Two thermophilic starters were simultaneously used, one composed of two strains of St. thermophilus - S18 and S19- and the second of three strains of Lb. helveticus L116, L122 and L124. The thermophilic strains came from a special collection of lactic acid bacteria isolated from Comté cheese (Institut national de la recherche agronomique, Poligny, France). The technological characteristics (growth, acidification and proteolysis) of these thermophilic strains are well known as they have been frequently used for mini-cheese manufacture in our laboratory [5].

\subsection{Genotypic characterization of lactococci}

\subsubsection{DNA extraction}

Bacterial cells were grown overnight at $37^{\circ} \mathrm{C}$ in M17 lactose broth. Genomic DNA was isolated by phenol-chloroform extraction, as previously described by De los Reyes-Gavilan et al. [14]. The quantity of DNA was evaluated with $0.8 \%$ agarose gel electrophoresis.

\subsubsection{RAPD experiments and analysis}

RAPD experiments were carried out as described by Tailliez et al. [39]. The three 
primers B6, B7 and B10 (Eurogentec, Angers, France) were used separately to screen the genotypic diversity of the 18 wild lactococcal isolates at strain level. One primer, B10, was chosen to follow the three strains of cocktail No. 2 used as the starter in the raw milk mini-cheese manufacture because it was the most discriminatory. RAPD profiles were compared using the GelCompar software, version 4.0 (Applied-Maths, Kortrijk, Belgium).

\subsection{Technological characterization of lactococci in milk}

\subsubsection{Presence or not of cell envelope protease, and lysogeny}

On FSDA agar (fast-slow differential agar) [27], Prt+ strains were white colonies with a pink acidification halo whereas Prtcolonies were smaller and transparent without the acidification halo.

Lysogenic strains were detected by exposure to mitomycin $\mathrm{C}$ with a final concentration of $1 \mu \mathrm{g} \cdot \mathrm{mL}^{-1}$ as described by Reyrolle et al. [37].

\subsubsection{Milk cultures of lactococci at a constant temperature of $30^{\circ} \mathrm{C}$}

Lactococci stored in glycerol at $-75^{\circ} \mathrm{C}$ were first pre-cultivated at $30{ }^{\circ} \mathrm{C}$ overnight in M17 broth containing $5 \mathrm{~g} \cdot \mathrm{L}^{-1}$ of lactose, and then immediately inoculated at $2 \%(\mathrm{v} / \mathrm{v})$ in milk A with the addition of $0.75 \mathrm{~g} \cdot \mathrm{L}^{-1}$ of litmus (DIFCO, Detroit, USA). Milk A was composed of $10 \%(\mathrm{w} / \mathrm{w})$ of an instant skim milk powder without antibiotics (ULN, Neuilly-sur-Seine, France) and sterilized. At this step, the strain cocktails were composed of equal quantities of each pure culture. Following that, the method described by Juillard and Richard [22] was used to prepare cultures for inoculation. The lowest uncoagulated dilution $\left(10^{-5}\right.$ for Prt+ strains and $10^{-2}$ for Prt- strains) was used to inoculate the milk cultures: $200 \mathrm{~mL}$ of milk B pre-heated at $80^{\circ} \mathrm{C} / 30 \mathrm{~min}$. Milk B was composed of $100 \mathrm{~g} \cdot \mathrm{L}^{-1}$ of low-heat milk powder (INRA-LRTL, Rennes, France) dissolved in sterile deionized water [38]. It was verified that this heat treatment did not affect the growth kinetics of the strains at $30{ }^{\circ} \mathrm{C}$. The inoculation rate was $0.2 \%(\mathrm{v} / \mathrm{v})$ and gave a constant cell number whether strains were Prt+ or Prt- with $\log 6.46 \pm 0.12$ $\left(\mathrm{cfu} \cdot \mathrm{mL}^{-1}\right)$. Cultures were incubated at $30{ }^{\circ} \mathrm{C}$ over a period of $24 \mathrm{~h}$.

The experiment was carried out once for pure cultures and twice for cultures of strain cocktails. Repetitions were always carried out independently from the strains stored at $-75^{\circ} \mathrm{C}$.

Growth kinetics were evaluated by sampling the milk cultures at $0,2,4,6,8$ and $24 \mathrm{~h}$.

Acidifying activity was estimated in each sample by measuring the $\mathrm{pH}(\mathrm{pH}-$ meter: Radiometer, Copenhagen, Denmark).

Proteolysis activity was measured, at 0 , 6 and $24 \mathrm{~h}$ of culture, by quantifying the release of free amino groups with the TNBS technique of Mc Kellar [31] modified by Bouton et al. [4]. The balance (production and consumption) of release of free amino groups between 0 and $6 \mathrm{~h}$ and between 0 and $24 \mathrm{~h}$ of culture was expressed in glycine equivalent units.

\subsubsection{Milk cultures of lactococci under the thermal gradient of Comté cheese}

Experiments were carried out as has been described for milk cultures at $30{ }^{\circ} \mathrm{C}$ except that, to remain as close as possible to starter preparation in cheese manufacture, lactococcal strains were prepared as follows: two $5 \mathrm{~mL}$ cultures of milk A with the addition of $0.75 \mathrm{~g} \cdot \mathrm{L}^{-1}$ of litmus were successively inoculated at $2 \%(\mathrm{v} / \mathrm{v})$, and lastly, a $100 \mathrm{~mL}$ culture of milk A was inoculated and incubated $9 \mathrm{~h}$ at $30^{\circ} \mathrm{C}$. The last $100 \mathrm{~mL}$ culture was used to constitute the two cocktails with an equal quantity of each pure culture for every strain composing them and to inoculate $200 \mathrm{~mL}$ of milk B at $0.2 \%$. Considering the experienced low 
contamination of milk B before heat treatment, we decided to suppress the heat treatment applied to milk B for milk cultures at $30^{\circ} \mathrm{C}$. Cultures were incubated over a period of $24 \mathrm{~h}$ under the thermal gradient commonly used in commercial Comté cheese manufacture (Fig. 2) and controlled by a thermal programmer (Coreci, Courbevoie, France).

This experiment was carried out twice independently, from strains stored at $-75^{\circ} \mathrm{C}$ for each of the pure cultures and cocktail cultures.

Growth kinetics and acidifying activity were evaluated as described for milk cultures at $30{ }^{\circ} \mathrm{C}$.

Proteolytic activity was not measured as we had already observed that release of free amino groups was close to the detection limit (data not shown).

\subsubsection{Milk culture of cocktail No. 2 in the presence of thermophilic starters}

In addition, cocktail No. 2 was cultivated in the presence of thermophilic starters - streptococci and lactobacilli - commonly used in Comté cheese manufacture. They were prepared as described above for lactococci but each culture was incubated for 6 and $8 \mathrm{~h}$ at $42^{\circ} \mathrm{C}$ for streptococci and lactobacilli, respectively. Strain cocktails were then inoculated in $400 \mathrm{~mL}$ of milk B at $0.2 \%, 0.12 \%$ and $0.08 \%(\mathrm{v} / \mathrm{v})$ for lactococci, streptococci and lactobacilli, respectively. Lactococci, streptococci and thermophilic lactobacilli were inoculated at the beginning, after one-and-a-half hours, and after two-hours of a two-hour milk maturation, respectively, to remain as close as possible to mini-cheese manufacture conditions.

\subsection{Mini-cheese manufacture}

Mini-cheeses (about $1 \mathrm{~kg}$ ) were made in a pilot cheese plant equipped with $12 \mathrm{~L}$ vats. Manufacture from renneting to the end of pressing was performed as described by Bouton et al. [4] with the same equipment. For this mini-cheese manufacture, the thermal gradient, the strain cocktails, the inoculation schedule and the inoculation rates were the same as those applied to milk cultures in the presence of thermophilic starters.

Cocktail No. 1 and cocktail No. 2 were used as mesophilic starters in February and July, respectively. Three mini-cheeses were manufactured at each season in two trials. In the first trial, two cheeses were manufactured, one with raw milk and one with the same milk but microfiltered. After pasteurization $\left(30 \mathrm{~s}\right.$ at $\left.72{ }^{\circ} \mathrm{C}\right)$, the cream was re-incorporated into the microfiltered milk. In the second trial two days later, one cheese was manufactured with reconstituted milk B to which $100 \mathrm{~g} \cdot \mathrm{L}^{-1}$ commercial UHT cream was added.

$\mathrm{pH}$ was measured using a penetration electrode (Mettler-Toledo, Paris, France).

Cocktail No. 2 was used in two more minicheese manufactures with both microfiltered milk collected in September and reconstituted milk, in order to test the repeatability of lactococcal growth during mini-cheese manufacture.

\subsection{Bacterial enumeration}

\subsubsection{Sample homogenization of milk and cheese samples}

Milk samples were homogenized with an Ultra-Turrax (model T25, IKALabortechnik, Staufen, Germany). Cheese samples were aseptically cut and the rind removed $(5 \mathrm{~mm})$. Following that, $10 \mathrm{~g}$ of the cheese sample were mixed with $90 \mathrm{~mL}$ of sterile tri-sodium citrate, $4 \mathrm{~g} \cdot \mathrm{L}^{-1}$, and homogenized with an Ultra-Turrax and a Stomacher blender (model Lab-Blender 400, Seward Medical UAC House, London, England).

\subsubsection{Colony counting and media for milk and cheese samples}

Consecutive dilutions were made using sterile water with $0.01 \mathrm{~g} \cdot \mathrm{L}^{-1}$ Bacto-peptone 
(Difco, Detroit, USA). Colony counting was performed in duplicate on plate agar after plating with a Spiral System (DS model, Saint-Nom-La-Bretèche, France). The following media were used:

- M17 lactose agar [40], aerobic incubation for $2 \mathrm{~d}$ at $30{ }^{\circ} \mathrm{C}$ for the milk cultures and at $20{ }^{\circ} \mathrm{C}$ for the cheese samples, for enumeration of lactococci;

- M17 lactose agar [40], aerobic incubation for $2 \mathrm{~d}$ at $45^{\circ} \mathrm{C}$ for enumeration of streptococci;

- De Man, Rogosa and Sharpe agar (MRS [15], Difco, Detroit, USA) at pH 5.4, anaerobic incubation for $3 \mathrm{~d}$ at $45^{\circ} \mathrm{C}$ for enumeration of lactobacilli;

- Kanamycin Aesculin Agar (KAA) (Merk, Nogent-sur-Marne, France), aerobic incubation for $2 \mathrm{~d}$ at $37^{\circ} \mathrm{C}$ for enterococci enumeration.

It was previously confirmed that, in our conditions, $99 \%$ of the colonies counted on M17 agar incubated at $45^{\circ} \mathrm{C}$ were streptococci colonies, $1 \%$ were lactococci or enterococci, and that no streptococci colonies were counted on MRS agar.

\subsection{Isolation of lactococci from mini-cheeses}

At each cheese manufacture sampling, fifteen colonies were isolated from M17 agar plates incubated for $2 \mathrm{~d}$ at $20^{\circ} \mathrm{C}$. Only isolates which were catalase-negative cocci growing in $\mathrm{M} 17$ lactose broth at $10^{\circ} \mathrm{C}$, and not at $45^{\circ} \mathrm{C}$ or with $65 \mathrm{~g} \cdot \mathrm{L}^{-1}$ of $\mathrm{NaCl}$ were considered to be lactococci. Lactococci, isolated during the manufacture of the raw milk cheese where cocktail No. 2 was used as a starter, were further characterized after purification.

\section{RESULTS}

\subsection{Genotypic characteristics of the 18 wild isolates}

The dendrogram depicted in Figure 1 shows the genetic diversity among the wild lactococcal isolates, as revealed by RAPD. Two clusters were observed at a Pearson's coefficient of $45 \%$. The first cluster, defined as cluster G1 by Taillez et al. [39], grouped all the isolates with the lactis genotype and phenotype, type strain CNRZ $142^{\mathrm{T}}$ and strain CNRZ 1076. The second cluster, defined as cluster G3 by Taillez et al. [39], grouped the four isolates with the cremoris genotype and the lactis phenotype. Affiliation to the cremoris genotype was previously determined for these four isolates by PCR with subspecies-specific primers [3] and with the strain CNRZ 269 (data not shown). All these results confirm the previous affiliation of the 18 wild isolates to Lactococcus lactis based on phenotypic characteristics. Genotypic characterization permitted further discrimination of genotypic subspecies, suggesting 18 different strains.

\subsection{Technological characteristics of pure cultures, in milk}

\subsubsection{Cell envelope protease and lysogeny}

Only two strains of the 18 wild strains were Prt-. For nine of the 18 wild strains $(50 \%)$, lysis occurred after addition of mitomycin $\mathrm{C}$, indicating that temperate phage had been released.

\subsubsection{Growth kinetics at constant temperature $\left(30^{\circ} \mathrm{C}\right)$}

The growth kinetics of lactococci over $24 \mathrm{~h}$ of culture in milk at $30{ }^{\circ} \mathrm{C}$ was different for Prt+ (16 strains) and Prt- (strains 2007 and 2013) strains (Tab. I). The exponential growth phase occurred between 0 and $6 \mathrm{~h}$ of culture for both Prt+ and Prtstrains. However, the stationary growth phase began earlier for Prt- strains, maximum from $6 \mathrm{~h}$ onwards, whereas it occurred between 6 and $24 \mathrm{~h}$ for Prt+ strains. The increase in the cell numbers of the Prt+ strains did not exhibit a large variability between strains. However, this variability was higher than the variability observed between the repetitions of the cocktail milk cultures. 


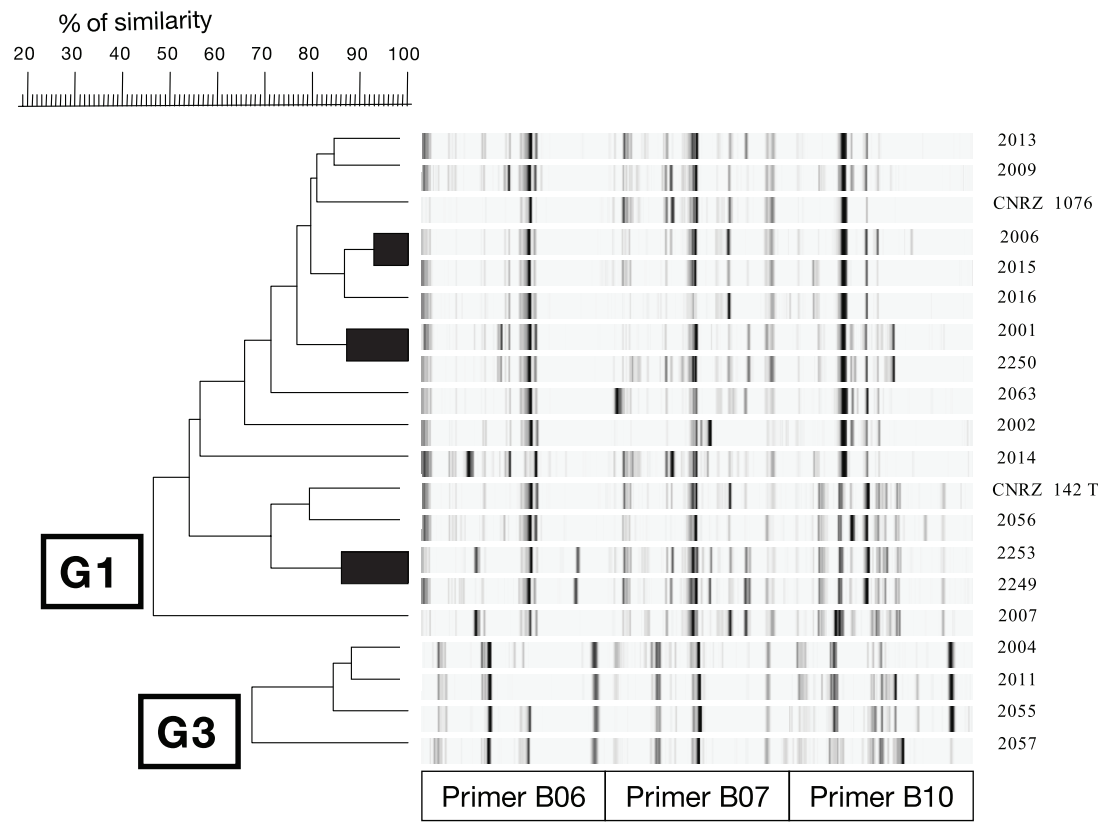

Figure 1. Dendrogram obtained from the RAPD profiles of 18 wild lactococci and strains CNRZ 1076 and CNRZ 142 ${ }^{\mathrm{T}}$. Clustering was performed using the Unweighted Pair Group Method with arithmetic Averages (UPGMA). Cluster G1 and cluster G3 were defined by Taillez et al. [39] grouping all the isolates with the lactis genotype and phenotype, and all the isolates with the cremoris genotype and the lactis phenotype, respectively.

Table I. Technological characterization of the 18 wild Lactococci strains with details for strains of the two strain cocktails cultivated in reconstituted milk at $30^{\circ} \mathrm{C}$. Technological characteristics were measured for one culture, with the exception of the two strain cocktails which were cultured twice.

\begin{tabular}{|c|c|c|c|c|c|c|}
\hline Strains or strain cocktails & $\Delta \mathrm{pH}_{0-6 \mathrm{~h}}$ & $\Delta \mathrm{pH}_{0-24 \mathrm{~h}}$ & $\begin{array}{l}\Delta \text { prot }_{0-6 \mathrm{~h}} \\
\text { (Eq glycine) }\end{array}$ & $\begin{array}{l}\Delta \text { prot } 0-24 \mathrm{~h} \\
\text { (Eq glycine) }\end{array}$ & $\begin{array}{l}\Delta \log _{0-6 h} \\
\left(\mathrm{cfu} \cdot \mathrm{mL}^{-1}\right)\end{array}$ & $\begin{array}{l}\Delta \log _{0-24 h} \\
\left(\mathrm{cfu} \cdot \mathrm{mL}^{-1}\right)\end{array}$ \\
\hline Means of Prt+ wild strains $(n=16)$ & 0.52 & 2.38 & +0.04 & +0.64 & 1.98 & 2.65 \\
\hline StD of Prt+ wild strains $(n=16)$ & 0.18 & 0.04 & 0.07 & 0.16 & 0.28 & 0.32 \\
\hline Means of Prt- wild strains $(n=2)$ & 0.23 & 0.80 & -0.04 & -0.06 & 1.83 & 1.86 \\
\hline StD of Prt- wild strains $(\mathrm{n}=2)$ & 0.06 & 0.17 & 0.01 & 0.04 & 0.05 & 0.3 \\
\hline 2006 & 0.64 & 2.40 & +0.16 & +0.81 & 2.29 & 2.72 \\
\hline 2063 & 0.59 & 2.31 & +0.14 & +0.85 & 2.30 & 2.79 \\
\hline 2001 & 0.79 & 2.41 & +0.02 & +0.53 & 1.51 & 3.14 \\
\hline 2004 & 0.41 & 2.33 & +0.05 & +0.95 & 1.86 & 3.10 \\
\hline 2056 & 0.20 & 2.42 & -0.01 & +0.71 & 1.72 & 2.54 \\
\hline Cocktail No. 1: 2001, 2006 and 2063 & 0.66 & 2.31 & +0.11 & +0.83 & 2.11 & 2.92 \\
\hline $\begin{array}{l}\text { Coefficient of variation }(\%) \text { between } \\
\text { duplicates }\end{array}$ & 0 & 0.2 & 15.5 & 2.5 & 1.9 & 2.7 \\
\hline Cocktail No. 2: 2001, 2004 and 2056 & 0.33 & 2.32 & +0.02 & +0.81 & 1.98 & 3.14 \\
\hline $\begin{array}{l}\text { Coefficient of variation (\%) between } \\
\text { duplicates }\end{array}$ & 4.5 & 0.6 & 33.3 & 2.8 & 5.8 & s1.3 \\
\hline
\end{tabular}




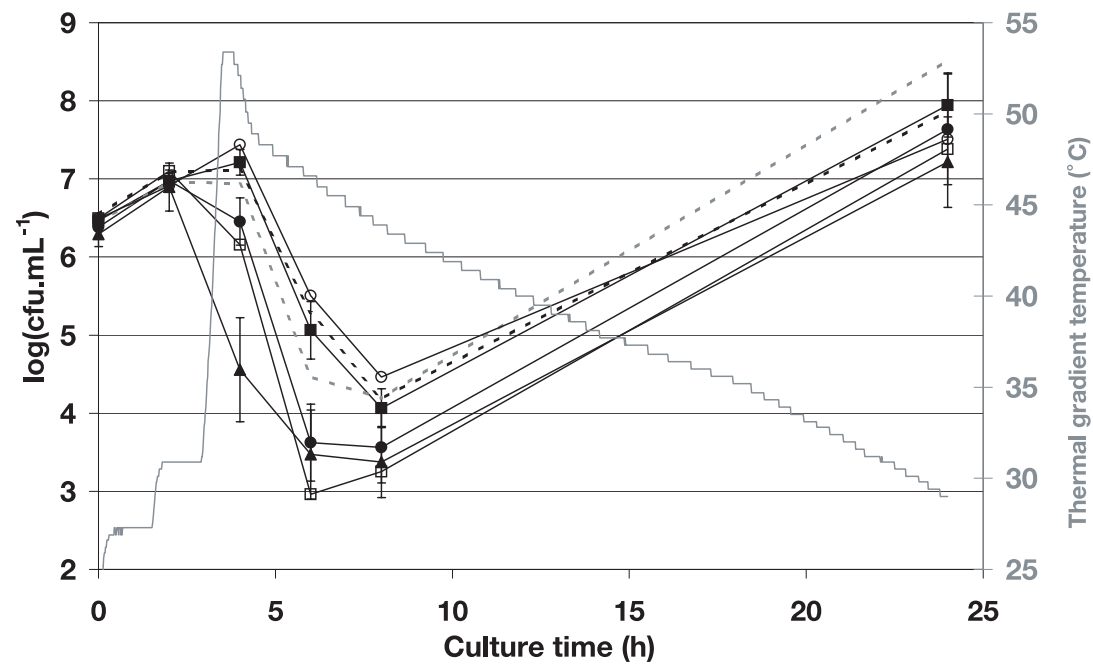

Figure 2. Growth kinetics of lactococci in milk cultures under the Comté cheese thermal gradient $(-)$. Black curves represent the three groups of heat resistance: $(\square)$ group A $(n=4)$; $(\mathbf{O})$ group B $(n=10)$; and $(\boldsymbol{\Delta})$ group $C(n=6)$, which are an average from "n" different pure strains for each group (each strain culture was already averaged from the duplicates of the same strain). Errors bars represent the diversity of growth kinetics between strains inside each group. (---) growth kinetics

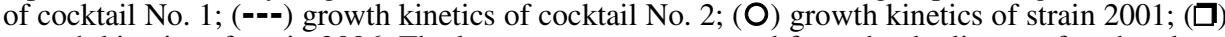
growth kinetics of strain 2006 . The latter curves are averaged from the duplicates of each culture with a maximum variation between duplicates of $\log \pm 0.9\left(\mathrm{cfu} \cdot \mathrm{mL}^{-1}\right)$.

\subsubsection{Acidifying activity at constant temperature $\left(30^{\circ} \mathrm{C}\right)$}

Table I presents the differences in $\mathrm{pH}$ between both 0 and $6 \mathrm{~h}$ and 0 and $24 \mathrm{~h}$ of culture in milk. The average initial $\mathrm{pH}$ of the milk was $6.63 \pm 0.02 \mathrm{pH}$ units. The decrease in $\mathrm{pH}$ observed with Prt- strains in the $24 \mathrm{~h}$ of milk culture was one-third of the decrease in $\mathrm{pH}$ observed with Prt+ strains (Tab. I). The standard deviation of the 16 Prt+ strains after $6 \mathrm{~h}$ of culture was higher than the standard deviation at the end of culture. This observation demonstrates the variability in acidification kinetics to attain the same final $\mathrm{pH}$ after $24 \mathrm{~h}$ of culture.

\subsubsection{Proteolytic activity at constant temperature $\left(30^{\circ} \mathrm{C}\right)$}

The results are shown in Table I. The two wild strains which exhibited the Prt- phenotype, strains 2007 and 2013, showed a negative balance for release of free amino groups after 6 and $24 \mathrm{~h}$ of milk culture, confirming their Prt- property. For all other strains, with the exception of strain 2056, free $-\mathrm{NH}_{2}$ release exhibited a positive balance after $6 \mathrm{~h}$ and $24 \mathrm{~h}$ of culture and a large diversity shown by the high standard deviations obtained.

\subsubsection{Growth kinetics under the thermal gradient of Comté cheese}

Figure 2 shows the growth kinetics of the 18 wild lactococcal strains and strains CNRZ 1076 and 1075 under the thermal gradient of Comté cheese. All growth kinetics exhibited three phases: a phase of positive growth before heating to $54{ }^{\circ} \mathrm{C}$, a phase of loss of culturability when the temperature increased or remained high, and a phase of positive growth and/or recovery 
of culturability when the temperature was again propitious for lactococcal growth. The cell number of all strains increased between 0 and $2 \mathrm{~h}$ of culture by $\log 0.59 \pm$ $0.17\left(\mathrm{cfu} \cdot \mathrm{mL}^{-1}\right)$. Large differences in kinetics occurred between 2 and $8 \mathrm{~h}$ of culture among the 18 strains so that three behaviors of strains (groups A, B and C) could be differentiated. Figure 2 shows the average curve of each group and standard deviations on these curves represent the diversity of growth kinetics inside each group. Group A clustered the four most heatresistant strains (strains 2001, 2009, 2016 and 2056) whose cell numbers still increased by $\log 0.24 \pm 0.33\left(\mathrm{cfu} \cdot \mathrm{mL}^{-1}\right)$ between 2 and $4 \mathrm{~h}$ of culture. Group B clustered ten strains (strains 2004, 2006, 2007, 2055, 2057, 2063, 2249, 2250, 2253 and CNRZ 1076) whose cell number decreased by only $\log 0.52 \pm 0.33\left(\mathrm{cfu} \cdot \mathrm{mL}^{-1}\right.$ ) between 2 and $4 \mathrm{~h}$ of culture. Group C clustered the six most heat-sensitive strains (strains 2002, 2011, 2013, 2014, 2015 and CNRZ 1075) whose cell number decreased drastically by $\log 2.34 \pm 0.66\left(\mathrm{cfu} \cdot \mathrm{mL}^{-1}\right)$ between 2 and $4 \mathrm{~h}$ of culture. Strain 2001 is the one whose cell number decreased the least by $\log -2.84\left(\mathrm{cfu} . \mathrm{mL}^{-1}\right)$ and strain 2006 the most, by $\log -4.14\left(\mathrm{cfu} \cdot \mathrm{mL}^{-1}\right)$ between 2 and $6 \mathrm{~h}$ of culture. The standard deviations between duplicates for each strain culture under the thermal gradient were much lower, with an average of $\log \pm 0.15\left(\mathrm{cfu} \cdot \mathrm{mL}^{-1}\right)$, than differences between strains. Consequently, one can conclude that lactococci exhibit variability of heat resistance under the thermal cycle of Comté cheese.

The growth kinetics between 8 and $24 \mathrm{~h}$ were not studied in detail but evolved similarly for the three groups. If $37^{\circ} \mathrm{C}$ is considered to be the highest temperature under which the lactococci can grow, they could have started to grow again after $14 \mathrm{~h}$ of culture. Therefore, their longest generation time would have been $0.78 \pm 0.15 \mathrm{~h}$. However, this is shorter than the generation time calculated, $1.14 \pm 0.36 \mathrm{~h}$, in the reconstituted milk at $30{ }^{\circ} \mathrm{C}$, their optimal growth temperature. As they were in a stressed physi- ological state at $8 \mathrm{~h}$ of culture and were at their optimal growth temperature only at $24 \mathrm{~h}$ of culture, it strongly suggests that recovery of culturability was associated with growth between 8 and $24 \mathrm{~h}$ of culture.

\subsubsection{Acidification under the thermal gradient of Comté cheese}

Acidification of strains under the thermal gradient was particularly weak, approximately $0.25 \mathrm{pH}$ unit after $24 \mathrm{~h}$ of culture, as shown in Figure 3 for cocktail No. 2.

\subsection{Selection of strains for use in cocktails}

Two or more strains are commonly present in the starters used in European countries to avoid a complete starter lysis by phage infection. Five Prt+ strains exhibiting different technological characteristics (Tab. I and Fig. 2) were chosen from the 18 wild strains to compose two cocktails of three strains. One non-lysogenic strain was selected for each cocktail (strain 2063 or 2004.)

The strains of cocktail No. 1 (strains 2001, 2006 and 2063) were selected to exhibit diversity in their heat resistance under the thermal gradient (Fig. 2) - strain 2001 exhibited the highest, strain 2006 the lowest heat resistance - while those of cocktail No. 2 (strains 2001, 2004 and 2056) were chosen to exhibit diversity in their technological characteristics at $30^{\circ} \mathrm{C}$ - strain 2004 exhibiting the highest proteolytic activity and strain 2001 the highest acidifying activity. Consequently, strain 2001 was common to both cocktails. Both cocktails should, as a result, exhibit similar heat resistance since strain 2001 is the most heat-resistant strain.

\subsection{Technological characteristics of strain cocktails and comparison with pure strains, in milk cultures}

\subsubsection{Lactococcal cocktails at constant temperature $\left(30^{\circ} \mathrm{C}\right)$}

After $24 \mathrm{~h}$ of culture, the two cocktails exhibited the same $\mathrm{pH}$, the same balance of 


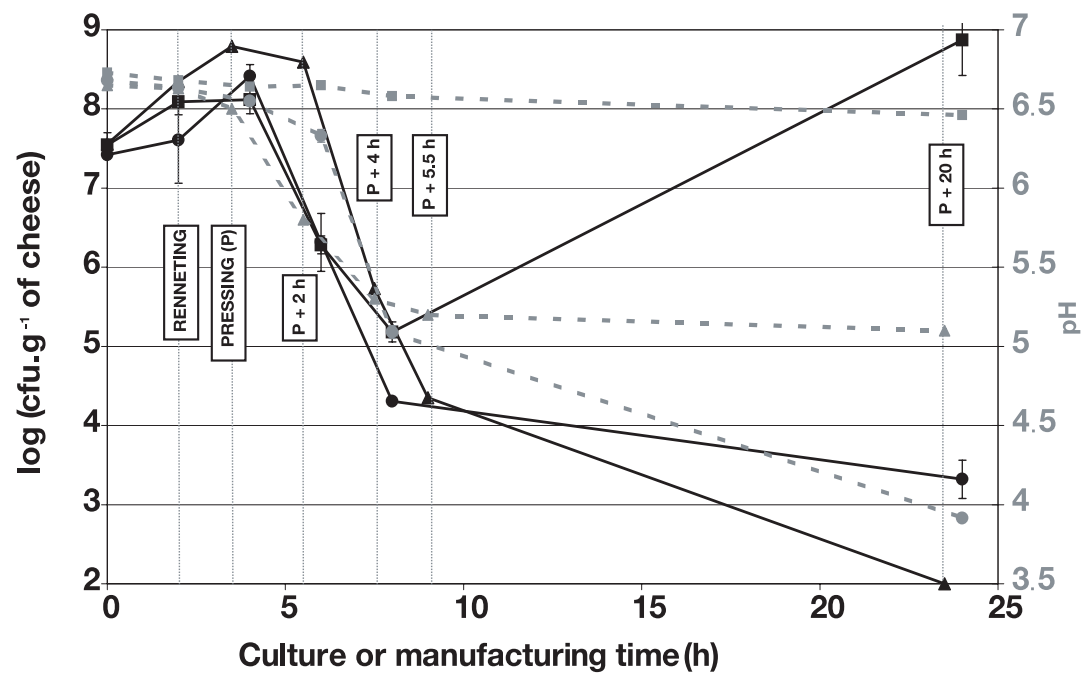

Figure 3. Growth kinetics (-) and pH (---) of cocktail No. 2 cultivated in reconstituted milk under the thermal gradient of Comté-type cheese, without thermophilic starters ( $\square$ ) and with thermophilic starters $(\mathbf{O})$, or in reconstituted milk mini-cheese $(\boldsymbol{\Delta})$. For all milk samples, $1 \log _{10}$ was added to cell numbers to express them in $\log _{10}\left(\mathrm{cfu} \cdot \mathrm{g}^{-1}\right.$ of cheese).

release of free amino groups and also the same increase in cell numbers. However, their kinetics of acidification and proteolysis (Tab. I) throughout the $24 \mathrm{~h}$ of milk culture were different. Cocktail No. 1 had higher acidifying and proteolytic activities than cocktail No. 2 between 0 and $6 \mathrm{~h}$ of culture.

Cocktail No. 1 had a growth rate, acidifying and proteolytic activities close to those of strains 2006 and 2063 but very different from those of strain 2001 (Tab. I). These parameters were different from what would be obtained if the cocktail activity were the addition of individual strain activities. Cocktail No. 2 had acidifying and proteolytic activities which were intermediate between those of strains 2004 and 2056 , but very different from those of strain 2001, and a growth rate close to that of strain 2004 (Tab. I). In both cocktails, these results suggest that the growth of strain 2001 was impaired when cultivated in milk in the presence of the two other strains of cocktails No. 1 and No. 2.

\subsubsection{Lactococcal cocktails under the thermal gradient of Comté cheese}

The two cocktails exhibited similar growth kinetics (Fig. 2). Cocktail No. 1 had the same growth kinetics as strain 2063 and cocktail No. 2 had the same growth kinetics as strain 2056, between 0 and $8 \mathrm{~h}$ of culture. Interactions between strains in cocktails modified the growth kinetics of strain 2001. As already observed in milk cultures at constant temperature, growth of strain 2001 was impaired within the two cocktails.

\subsubsection{Cocktail No. 2 in the presence of thermophilic starters under thermal gradient}

The growth kinetics of the thermophilic starters exhibited two principal phases under the thermal gradient of Comte cheese (data not shown): an exponential growth from inoculation to $8 \mathrm{~h}$ of culture for streptococci, and from $4 \mathrm{~h}$ to more than $8 \mathrm{~h}$ of culture after a lag phase for lactobacilli, and a stationary phase at the maximum levels 


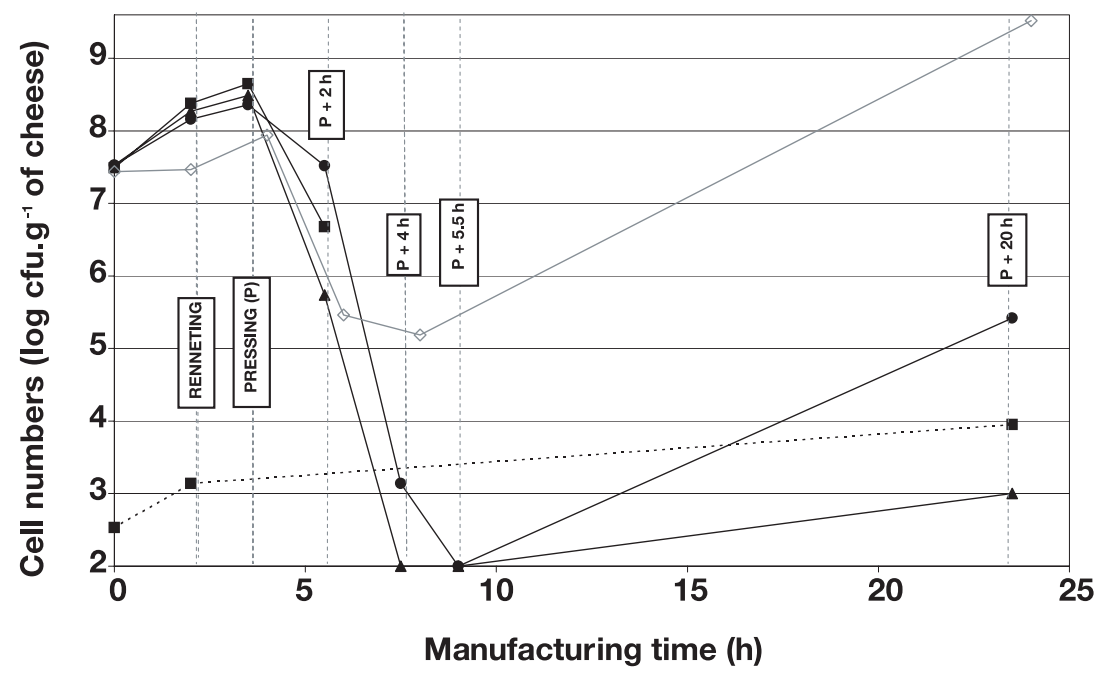

Figure 4. Growth kinetics of cocktail No. 1 in Comté-type mini-cheeses manufactured from raw milk, $(\boldsymbol{\Delta})$ microfiltered milk and $(\mathbf{O})$ reconstituted milk and in $(O)$ milk culture under the Comté cheese thermal gradient. Growth kinetics of enterococci (-----) in raw milk cheese. For all milk samples before pressing, $1 \log _{10}$ was added to cell numbers to express them in $\log _{10}\left(\mathrm{cfu}^{\mathrm{g}} \cdot \mathrm{g}^{-1}\right.$ of cheese).

of population which were $\log 8.82\left(\mathrm{cfu} \cdot \mathrm{mL}^{-1}\right)$ for streptococci and $\log 8.56\left(\mathrm{cfu} \cdot \mathrm{mL}^{-1}\right)$ for lactobacilli. As shown in Figure 3 for cocktail No. 2, the presence of thermophilic starters modified the growth kinetics of lactococci in milk culture under the thermal gradient of Comté cheese. The loss of culturability was increased by $\log 1\left(\mathrm{cfu} \cdot \mathrm{mL}^{-1}\right)$ in the presence of thermophilic starters between 6 and $8 \mathrm{~h}$ of culture due to the decrease in $\mathrm{pH}$ from 6.3 to 5.1 , a pH unfavorable to growth of lactococci. For the same reason, the increase in cell numbers between 8 and $24 \mathrm{~h}$ of culture observed without thermophilic starters was absent.

\subsection{Lactococcal growth in Comté-type mini-cheeses}

\subsubsection{The growth kinetics of the lactococcal cocktails in mini-cheeses manufactured from different types of milks}

Mini-cheeses were manufactured from three different milks - raw, microfiltered and reconstituted - combined with the two lactococcal cocktails. The growth kinetics of the thermophilic starters were modified compared with their growth kinetics in milk cultures (data not shown). Their growth kinetics in cheese were similar to those described by Turner et al. [41] during pressing of Swiss-type cheeses. The shorter exponential growth phases in cheese than in milk for both streptococci and lactobacilli, with either similar or higher growth rates, provided an earlier $\mathrm{pH}$ decrease in cheese than in milk cultures (Fig. 3). If we consider the ten-fold concentration due to pressing $[1,19]$, maximum population levels of thermophilic starters were lower in cheese than in milk by about $\log 1$ ( $\mathrm{cfu} \cdot \mathrm{g}^{-1}$ of cheese).

Whatever the type of milk and cocktail, the growth kinetics of the two cocktails exhibited the three phases previously described for the lactococcal strain cultures in reconstituted milk, under the thermal gradient, in the presence of thermophilic starters (Fig. 3). Whatever the cocktail used, lactococci lost culturability later in mini-cheese manufactured from reconstituted milk than in liquid reconstituted milk (Figs. 3 and 4). Cell number 


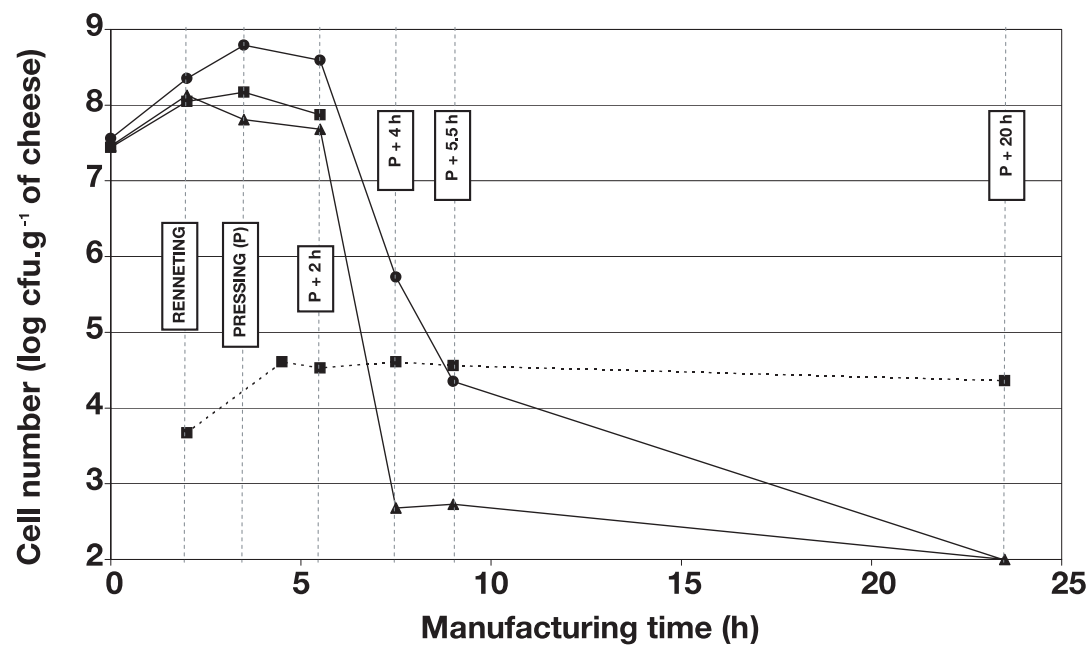

Figure 5. Growth kinetics of cocktail No. 2 in Comté-type mini-cheeses manufactured from (ם) raw milk, (A) microfiltered milk and (O) reconstituted milk. Growth kinetics of enterococci (-----) in raw milk cheese. For all milk samples before pressing, $1 \log _{10}$ was added to cell numbers to express them in $\log _{10}\left(\mathrm{cfu} \cdot \mathrm{g}^{-1}\right.$ of cheese).

increase was already higher in cheese than in milk cultures before heating to $54{ }^{\circ} \mathrm{C}$. However, the decrease in $\mathrm{pH}$ of cheese between pressing and $2 \mathrm{~h}$ of pressing was $0.7 \mathrm{pH}$ unit whereas the decrease in $\mathrm{pH}$ of milk culture during the same period was $0.2 \mathrm{pH}$ unit (Fig. 3). Lactococci should thus have been more acid-stressed in cheese than in milk culture during this period.

Growth between 0 and $4 \mathrm{~h}$ of manufacture was different according to the cocktail and the type of milk used (Figs. 4 and 5). In these present manufactures, growth of cocktail No. 2 was better in cheese made from reconstituted milk, while growth of cocktail No. 1 was better in cheese made from raw or microfiltered milk. In this case, the differences between cheeses manufactured from raw/microfiltered milk and reconstituted milk may be linked to the variability in raw milk composition according to the period at which it was collected.

Considering that reconstituted milk did not change from the first manufacture to the second, cocktail No. 2 exhibited a better resistance to the combined stresses
heating/pH decrease than cocktail No. 1 during the pressing of the mini-cheeses.

Whatever the cocktail used, loss of culturability exhibited different kinetics according to the milk from which mini-cheeses were manufactured: it was very drastic with microfiltered milk. In raw milk mini-cheeses only, loss of culturability was difficult to assess because characterization tests demonstrated that all the colonies, isolated from $4 \mathrm{~h}$ of pressing from raw milk minicheeses and counted on M17 agar at $20^{\circ} \mathrm{C}$, were enterococci colonies. This was confirmed by counting on a specific medium for enterococci (KAA), which demonstrated that the population level of enterococci increased during manufacture of raw milk mini-cheeses only.

In order to test the repeatability of growth kinetics for lactococci during minicheese manufacture, cocktail No. 2 was used in two more manufactures made with both microfiltered milk collected in September and with reconstituted milk (Fig. 6). In spite of high variation between manufactures, these results confirmed that loss of 


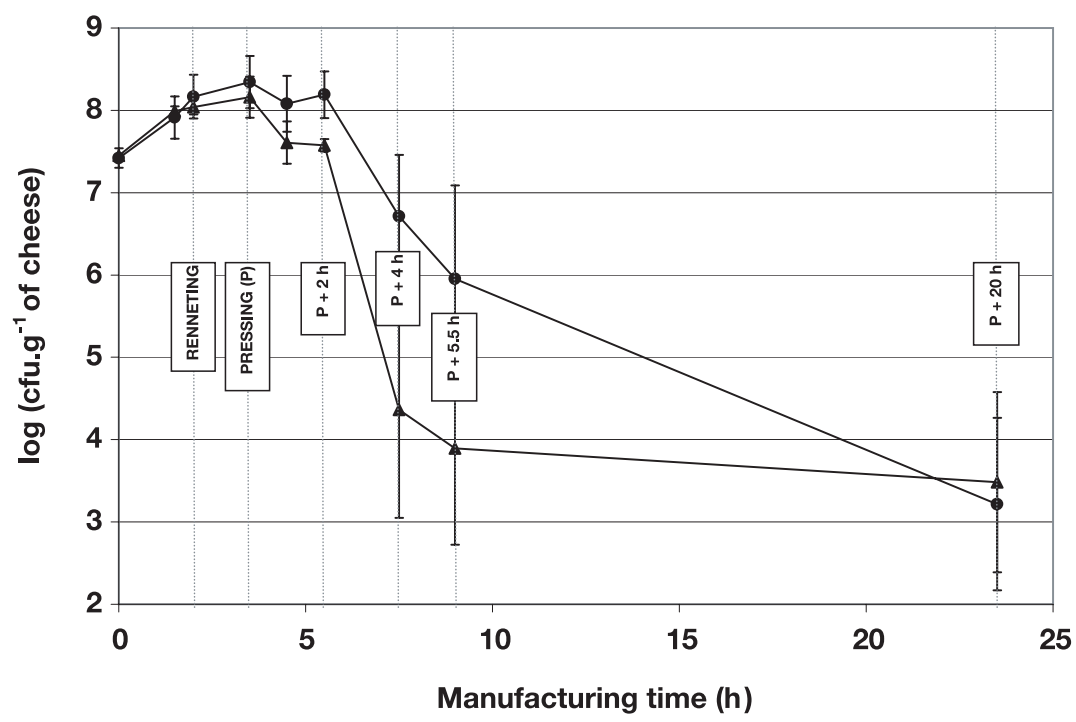

Figure 6. Growth kinetics of lactococci during mini-cheese manufacture made with microfiltered milk ( $\mathbf{\Delta})$ and reconstituted milk $(\boldsymbol{O})$. Average and standard deviations of three manufactures are shown for each curve. For all milk samples before pressing, $1 \log _{10}$ was added to cell numbers to express them in $\log _{10}\left(\mathrm{cfu} \cdot \mathrm{g}^{-1}\right.$ of cheese $)$.

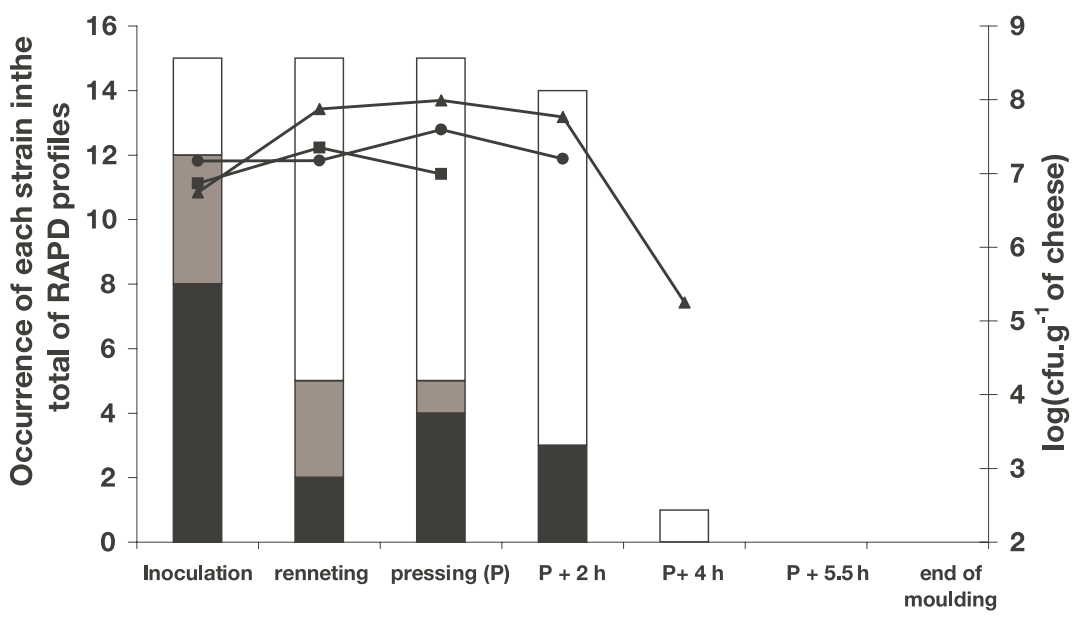

Manufacturing stages

Figure 7. Occurrence of each lactococcal strain present in cocktail No. 2 throughout the manufacture of raw milk Comté-type cheese. The number of RAPD profiles identical to the RAPD

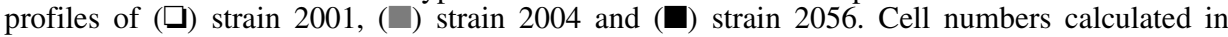
proportion of the total number of lactococci for $(\boldsymbol{\Delta})$ strain 2001, (ם) strain 2004, and (O) strain 2056. For all milk samples before pressing, $1 \log _{10}$ was added to cell numbers to express all of them in $\log _{10}\left(\mathrm{cfu} \cdot \mathrm{g}^{-1}\right.$ of cheese). 
culturability occurred earlier and to a greater extent in microfiltered milk than in reconstituted milk. Growth kinetics between inoculation and pressing tended to be better in reconstituted milk than in microfiltered milk for this cocktail No. 2.

\subsubsection{Growth kinetics of individual lactococcal strains of cocktail No. 2 in raw milk mini-cheese}

RAPD enables discrimination at the strain level and was performed on the isolates from the cheese or milk during raw milk manufacture in order to compare the growth kinetics of individual strains of cocktail No. 2 in milk and in cheese. Figure 7 shows that no wild lactococci from raw milk could be isolated as all the profiles represented the three strains used as starters. From $4 \mathrm{~h}$ of pressing, only enterococci colonies could be isolated.

The cell number of each individual strain (Fig. 7) was estimated by the frequency of their isolates and the total number of lactococci at each stage (Fig. 5). Strain 2001 dominated the two other strains from renneting to $4 \mathrm{~h}$ of pressing. Its cell number increased before renneting, remained at the same level until after $2 \mathrm{~h}$ of pressing and decreased between 2 and $4 \mathrm{~h}$ of pressing. The cell numbers of strains 2004 and 2056 remained similar from inoculation to pressing and $2 \mathrm{~h}$ of pressing, respectively, and then decreased drastically within two hours.

\section{DISCUSSION}

The eighteen isolates of wild lactococci isolated from raw milk destined for different dairies, or from natural starter cultures dedicated to Comté cheese manufacture, exhibited eighteen different genotypes, and thus eighteen different strains. Strains with a cremoris genotype seem to be widespread, representing $22 \%$ of the present strains and $37.5 \%$ of the isolates of Desmasures et al. [16]. The eighteen different RAPD patterns demonstrate the natural genetic diversity of wild lactococci isolated from raw milk destined for Comté cheese dairies. All these isolates originated from different places in the Comté cheese DPO (Denomination of Protected Origin) area, with the exception of strains 2056, 2057 and 2063. The latter strains were isolated from the same natural starter, attesting to the diversity in a given whey with which the natural starter was made.

The eighteen wild strains exhibited only the lactis phenotype, but very different acidifying and proteolysis activities when cultivated at a constant temperature in milk. These activities were in the range of those previously described for lactococci. Measurement of their acidifying activity in milk at a constant temperature $\left(30^{\circ} \mathrm{C}\right)$ revealed that these wild lactococcal strains were not acidifying strains. The average $\mathrm{pH}$ reached after $6 \mathrm{~h}$ at $30^{\circ} \mathrm{C}$ was 6.11 . This confirms the results of Cogan et al. [12] who found that only $8.3 \%$ of 1582 lactococci isolated from different raw milk products were able to acidify reconstituted milk to $\mathrm{pH}<5.3$ in $6 \mathrm{~h}$. The present results demonstrate a high variability in acidification kinetics, indicating that acidification rates evolved differently between strains to reach the same final $\mathrm{pH}$. This corroborates the results of Casalta et al. [8]. The large diversity of proteolytic activity at $30^{\circ} \mathrm{C}$ was in accordance with the results obtained by Mannu et al. [30] for wild lactococci isolated from Pecorino Sardo cheeses made from raw milk.

The present study reveals the large diversity of growth kinetics among 18 lactococcal strains cultivated in milk under a Comté cheese thermal gradient. Individual wild lactococcal strains exhibited very different growth kinetics depending on their resistance to heating to $54{ }^{\circ} \mathrm{C}$. The differences in growth during and after heating were responsible for the variability observed between strains. The most heat-sensitive strains lost culturability during the heating period, while the most heat resistant strains did so only after the heating period. Chamba [9] has also reported this range of 
culturability loss for lactococci under the Emmental cheese thermal gradient but growth kinetics have not been depicted. Thus, it is impossible to compare the present kinetics with the results of Chamba's study. The decrease in cell numbers could be the consequence of cell lysis and/or the loss of culturability of cells that remained otherwise viable [25]. The calculation of growth rates during the third phase has indicated that the two phenomena occurred. Lysis has been demonstrated during the phase of culturability loss for lactococci grown in milk and subjected to an increase in temperature from $30{ }^{\circ} \mathrm{C}$ to $40{ }^{\circ} \mathrm{C}$ or to heat-shocks of $55^{\circ} \mathrm{C}$ and $70{ }^{\circ} \mathrm{C}$ for $20 \mathrm{~s}[24,35]$. Lysis can also be stimulated by thermal induction of a prophage [32, 35]. But, in this study, lysogenic strains were not the most heat-sensitive ones. It, therefore cannot be a reason for the heat resistance variability observed.

Besides the heat resistance of each strain, the growth kinetics of individual strains was influenced by the associated strains and by the culture type, milk vs. cheese. In milk culture made with reconstituted milk, the growth of strain 2001 was systematically impaired when associated with the other strains of cocktails No. 1 or No. 2, both at constant temperature and under the thermal gradient. One can speculate that strains for which cell numbers increased early at high growth rates released in the milk some factors necessary for the growth of strains such as strain 2001 which grew only later at a high growth rate. On the contrary, in cheese inoculated with cocktail No. 2, strain 2001 outgrew strain 2056 before the heating step, and this latter strain did not grow at all. One explanation for the differences between lactococcal growth in cheese and milk would be that the factors promoting the growth of strain 2001 were present in the raw milk which was used for the cheese manufacture under examination. In this configuration, the growth of lactococci in cheese would correspond to the growth of strain 2001, which was the most heat resistant strain, and would explain the later loss of culturability observed in cheese vs. milk, in spite of the faster acidification in cheese than in milk. Another explanation could be that some general factors other than those controlled for milk culture influenced lactococcal growth in cheese like such as: the presence of fat matter, more importantly oxygenation of milk during cheese manufacture, or the presence of a solid matrix in cheese by the action of rennet. It has been observed that bacterial colonies were in close contact with the fat globule membrane in the cheese matrix [26] and, therefore, fat could protect them. However, how does one explain that some strains were more protected than others? Oxygenation highly influenced growth and acidification of mesophilic starters [2]. Either lactococcal strains could respond differently to the presence of a higher level of molecular oxygen and derived products through different reducing abilities [7]; or, in the cheese matrix, bacteria are organised in colonies that could be perhaps sufficiently far from each other not to be submitted to the competition for nutrients that was suggested in a liquid matrix; or, the action of chymosin in rennet releases nitrogen products from $\alpha_{\mathrm{s} 1}$-casein, for example, fragment $\alpha_{\mathrm{s} 1}-\mathrm{CN}(\mathrm{f} 1-23)$, which can be used for growth by Prt+ strains [17] to different extents according to the strain.

In raw milk cheese, enterococci numbers were too high to be able to count lactococci after $4 \mathrm{~h}$ of pressing. However, they did not seem to influence lactococci as there was no difference between lactococcal growth in microfiltered milk and in raw milk before $2 \mathrm{~h}$ of pressing.

Lactococci had never previously been selected according to specific criteria for cooked cheese manufacture as the thermophilic starters have been. However, the present work demonstrates, in agreement with Chamba's conclusions [9], that for complex manufacturing such as cooked cheese, tests in milk are difficult to adapt to conditions prevailing in cheese. Growth of 
lactococci observed in the experimental mini-cheeses was less repeatable than in milk cultures. It could not be entirely reproduced during cultures in milk, despite the fact that strains were cultivated in milk under conditions as close as possible to those imposed by the manufacture of cooked cheese. For this reason, the tests in milk using the thermal gradient proposed here can be a tool for comparing heat resistance of individual strains because diversity exists. However, this cannot be used to predict the growth kinetics of strain cocktails in cooked cheese manufacture, because certain conditions prevailing in cheese and exerting an influence on lactococcal growth were probably not taken into account in the tests in milk, as discussed above. To permit the best correspondence of lactococcal growth to that observed in cheese manufacture, the use of the same thermophilic starters due to the dependence on $\mathrm{pH}$, the same milk due to the major effect of the type of milk and the same thermal gradient must be advised. Furthermore, to improve the test in milk, it may be possible to take into account some of the conditions prevailing in cheese, such as oxygenation. However, if it is a problem of liquid vs. solid matrix, by using rennet, the manufacture of cheese seems to be the most suitable.

The wild lactococcal strains were collected to be used in the manufacture of Comté cheese, in which their role is still not clear. It is now essential to appreciate the role of lactococcal strains used in milk maturation during Comté cheese manufacture. Cheeses made with cocktails of lactococcal strains with different technological properties (acidifying, heat-sensitive or proteolytic cocktails) may, therefore, be useful in revealing the properties responsible for the role of lactococci in Comté cheese manufacture.

\section{ACKNOWLEDGMENTS}

The authors are grateful to F. Dufrene for his technical help and to G. Duboz for manufactur- ing the mini-cheeses. The authors express their appreciation to M.C. Chopin for technical and scientific help with the detection of lysogeny. The authors are thankful to M. McLoughlin and H. Lamprell for correcting the English. We would also like to thank the Laboratory of Dairy Technology Research (INRA-LRTL, Rennes, France) for providing the low-heat milk powder.

\section{REFERENCES}

[1] Accolas J.P., Veaux M., Vassal L., Mocquot G., Évolution de la flore lactique thermophile au cours du pressage des fromages à pâte cuite, Lait 573-574 (1978) 118-132.

[2] Aubert C., Capelle N., Jeanson S., Eckert H., Diviès C., Cachon R., Le potentiel d'oxydoréduction et sa prise en compte dans les procédés d'utilisation des bactéries lactiques, Sci. Aliments 22 (2002) 177-187.

[3] Beimfohr C., Ludwig W., Schleifer K.H., Rapid genotypic differentiation of Lactococcus subspecies and biovar, Syst. Appl. Microbiol. 20 (1997) 216-221.

[4] Bouton Y., Guyot P., Dasen A., Grappin R., Activité protéolytique de souches de lactobacilles thermophiles isolées de levains et de Comté. I. Validation sur minifromages des techniques de laboratoire, Lait 73 (1993) 265-279.

[5] Bouton Y., Guyot P., Grappin R., Preliminary characterization of microflora of Comté cheese, J. Appl. Microbiol. 85 (1998) 123-131.

[6] Boutrou R., Sepulchre A., Pitel G., Durier C., Vassal L., Gripon J.C., Monnet V., Lactococcal lysis and curd proteolysis: two predictable events important for the development of cheese flavour, Int. Dairy J. 8 (1998) 609-616.

[7] Cachon R., Jeanson S., Aldarf M., Diviès C., Characterization of lactic acid starters based on acidification and reduction activities, Lait 82 (2002) 281-288.

[8] Casalta E., Vassal Y., Desmazeaud M.J., Casabianca F., Comparaison de l'activité acidifiante de souches de Lactococcus lactis isolées de lait et de fromage de Corse, Lebensm. Wiss. Technol. 28 (1995) 291-299.

[9] Chamba J.F., L'emmental, un écosystème complexe. Conséquences sur la sélection et l'utilisation des ferments, Sci. Aliments 20 (2000) 37-54.

[10] Chamba J.F., Prost F., Mesure de l'activité acidifiante des bactéries lactiques thermophiles utilisées pour la fabrication des fromages à pâte cuite, Lait 69 (1989) 417-431. 
[11] Chamba J.F., Duong C., Fazel A., Prost F., Sélection des souches de bactéries lactiques, in: De Roissart H., Luquet F.M. (Eds.), Bactéries lactiques, Vol. 1, Lorica, Uriage, France, 1994, pp. 499-521.

[12] Cogan M.T., Barbosa M., Beuvier E., BianchiSalvadori B., Cocconcelli P.S., Fernandes I., Gomez J., Gomez R., Kalantzopoulos G., Ledda A., Medina M., Rea M.C., Rodriguez E., Characterization of the lactic acid bacteria in artisanal dairy products, J. Dairy Res. 64 (1997) 409-421.

[13] Corroler D., Mangin I., Desmasures N., Guéguen M., An ecological study of lactococci isolated from raw milk in the Camembert cheese registered designation of origin area, Appl. Environ. Microbiol. 64 (1998) 4729-4735.

[14] De los Reyes-Gavilan C.G., Limsowtin G.K.Y., Tailliez P., Séchaud L., Accolas J.P., A Lactobacillus helveticus-specific DNA probe detects restriction fragment length polymorphisms in the species, Appl. Environ. Microbiol. 58 (1992) 3429-3432.

[15] De Man J.C., Rogosa M., Sharpe M.E., A medium for the cultivation of lactobacilli, J. Appl. Bacteriol. 23 (1960) 130-135.

[16] Desmasures N., Mangin I., Corroler D., Guéguen M., Characterization of lactococci isolated from milk produced in the Camembert region of Normandy, J. Appl. Microbiol. 85 (1998) 999-1005.

[17] Exterkate F.A., Alting A.C., The role of starter peptidases in the initial proteolytic events leading to amino acids in Gouda cheese, Int. Dairy J. 5 (1995) 15-28.

[18] Fox P.F., McSweeney P.L.H., Proteolysis in cheese during ripening, Food Rev. Int. 12 (1996) 457-509.

[19] Gilles J., Turner K.W., Martley F.G., Swisstype cheese. I - Manufacturing and sampling procedures, N. Z. J. Dairy Sci. Technol. 18 (1983) 109-115.

[20] Giraffa G., Neviani E., Carminati D., Acidifying activity of Streptococcus thermophilus under a thermal cycle process, Milchwissenschaft 48 (1993) 128-130.

[21] Heap H.A., Lawrence R.C., Recent modifications to the New Zealand activity test for Cheddar cheese starters, N. Z. J. Dairy Sci. Technol. 16 (1981) 91-94.

[22] Juillard V., Richard J., Étude de l'interaction entre souches protéolytiques de streptocoques lactiques mésophiles et leurs variants non protéolytiques, au cours de leur croissance dans le lait, Lait 69 (1989) 291-304.

[23] Juillard V., Richard J., Indirect interaction in milk between proteolytic and isogenic nonproteolytic strains of Lactococcus lactis. I.
Effect of pre-culturing by a non-proteolytic variant, Lait 70 (1990) 425-438.

[24] Kamaly K.M., Bacteriolysis and peptidolysis of cheese ripening lactic lactococci, in: Book of abstracts, sixth symposium on Lactic Acid Bacteria, Veldhoven, Pays-Bas, 1999.

[25] Kell D.B., Kaprelyants A.S., Weichart D.H., Harwood C.R., Barer M.R., Viability and activity in readily culturable bacteria: a review and discussion of the practical issues, Antonie Leeuwenhoek 73 (1998) 169-187.

[26] Laloy E., El Soda M., Simard R.E., Vuillemard J.C., Evolution of starter bacteria in the cheese microstructure during ripening, in: Book of abstracts, Symposium IDF, Besançon, France, 1996, p. 38.

[27] Limsowtin G.K.Y., Terzaghi B.E., Agar medium for the differentiation of "fast" and "slow" coagulating cells in lactic streptococcal cultures, N. Z. J. Dairy Sci. Technol. 11 (1976) 65-66.

[28] Lynch C.M., McSweeney P.L.H., Fox P.F., Cogan T.M., Drinan F.D., Contribution of starter lactococci and non-starter lactobacilli to proteolysis in Cheddar cheese with a controlled microflora, Lait 77 (1997) 441-459.

[29] Mannu L., Paba A., Genetic diversity of lactococci and enterococci isolated from homemade Pecorino Sardo ewes' milk cheese, J. Appl. Microbiol. 92 (2002) 55-62.

[30] Mannu L., Paba A., Pes M., Scintu M.F., Genotypic and phenotypic heterogeneity among lactococci isolated from traditional Pecorino Sardo cheese, J. Appl. Microbiol. 89 (2000) 191-197.

[31] Mc Kellar R.C., Development of off-flavors in ultra high temperature and pasteurized milk as a function of proteolysis, J. Dairy Sci. 64 (1981) 2138-2145.

[32] Meijer W., Dobbelaar C., Hugenholtz J., Thermoinducible lysis in Lactococcus lactis subsp. cremoris SK 1110: implications for cheese ripening, Int. Dairy J. 8 (1998) 275-280.

[33] Michel V., Martley F.G., Streptococcus thermophilus in Cheddar cheese - production and fate of galactose, J. Dairy Res. 68 (2001) 317-325.

[34] Neviani E., Divizia R., Abbiati E., Gatti M., Acidification activity of thermophilic lactobacilli under the temperature gradient of Grana cheese making, J. Dairy Sci. 78 (1995) 1248-1252.

[35] O’Sullivan D., Ross R.P., Fitzegerald G.F., Coffey A., Use of prophage integrase genes to predict autolysis in strains of Lactococcus lactis during cheese cooking, in: Book of abstracts, sixth symposium on Lactic Acid Bacteria, Veldhoven, Pays-Bas, 1999. 
[36] Pearce L.E., Activity tests for cheese starter cultures, N. Z. Dairy Sci. Assoc. Conference, N. Z. J. Dairy Sci. Technol. 4 (1969) 246-247.

[37] Reyrolle J., Chopin M.C., Letellier F., Novel G., Lysogenic strains of lactic acid streptococci and lytic spectra of their temperate bacteriophages, Appl. Environ. Microbiol. 43 (1982) 349-356.

[38] Schuck P., Piot M., Méjean S., Fauquant J., Brulé G., Maubois J.L., Déshydratation des laits enrichis en caséine micellaire par microfiltration; comparaison des propriétés des poudres obtenues avec celles d'une poudre de lait ultra-propre, Lait 74 (1994) 47-63.

[39] Tailliez P., Tremblay J., Ehrlich S.D., Chopin A., Molecular diversity and relationship within Lactococcus lactis, as revealed by randomly amplified polymorphic DNA (RAPD), Syst. Appl. Microbiol. 21 (1998) 530-538.

[40] Terzaghi B.E., Sandine W.E., Improved medium for lactic streptococci and their bacteriophages, Appl. Microbiol. 29 (1975) 807-813.

[41] Turner K.W., Morris H.A., Martley F.G., Swiss-type cheese. II. Role of thermophilic lactobacilli in sugar fermentation, N. Z. J. Dairy Sci. Technol. 18 (1983) 117-123.

[42] Weerkamp A.H., Klijn N., Neeter R., Smit G., Properties of mesophilic lactic acid bacteria from raw milk and naturally fermented raw milk products, Neth. Milk Dairy J. 50 (1996) 319-332. 